\title{
Intracystic Papillary Carcinoma of the Breast in Males. In Search of the Optimal Treatment for this Rare Disease
}

\author{
Michael Stamatakos ${ }^{\mathrm{a}}$ Charikleia Stefanaki $^{\mathrm{a}} \quad$ Theodora Stasinou $^{\mathrm{a}}$ \\ Evaggelia Papantoni $^{\mathrm{a}}$ Ioannis Alexiou ${ }^{\mathrm{b}}$ Konstantinos Kontzoglou ${ }^{\mathrm{b}}$ \\ a4th Department of Surgery, \\ ${ }^{\mathrm{b}}$ 2nd Department of Propaedeutic Surgery, Medical School, University of Athens, Laiko General Hospital, Athens, Greece
}

\author{
Keywords \\ Breast cancer · Man · IPC $\cdot$ DCIS · Papilloma
}

\section{Summary}

Intracystic papillary carcinoma (IPC) of the breast in men is an extremely infrequent disease, and it appears to have a good prognosis. Because of this, histological findings are of great importance in the decision-making process regarding treatment. Clinical examination, radiological and histological assessments are required for early detection. Adequate surgical excision with negative margins is mandatory. However, the role of sentinel node biopsy has not been evaluated in male IPC. It appears that sentinel node biopsy may be an excellent alternative to radical axillary dissection in patients with IPC and associated ductal carcinoma in situ or invasive carcinoma. Nevertheless, due to the rarity of IPC and its confusing histopathological classification and staging, there are still no clear guidelines as far as IPC treatment is concerned.

\section{Introduction}

Male breast cancer is a rare tumor entity due to the hypoplastic state of the male mammary gland. It accounts for less than $1 \%$ of all breast cancers $[1,2]$. Intracystic papillary carcinomas (IPCs) are therefore extremely uncommon, and only limited data are available. According to a variety of reports, it appears that a relationship may exist between elevated serum prolactin levels and breast cancer [3, 4]. According to Okada et al. [5], there is a close relationship between bilateral male breast cancer and hyperprolactinemia. With regard to the

\author{
Schlüsselwörter \\ Mammakarzinom · Mann · IPC · DCIS · Papillom
}

\section{Zusammenfassung}

Intrazystische papilläre Mammakarzinome (IPC) des Mannes sind eine extrem seltene Erkrankung mit einer anscheinend guten Prognose. Die histologischen Befunde sind daher von großer Bedeutung für die Therapieentscheidung. Klinische, radiologische und histologische Untersuchungen sind für die Früherkennung entscheidend. Die adequate chirurgische Entfernung mit negativem Schnittrand ist zwingend erforderlich. Die Rolle der Sentinel-Lymphknotenbiopsie beim IPC des Mannes ist bisher noch nicht untersucht worden. Es scheint jedoch, dass sie eine exzellente Alternative zur radikalen Achselhöhlendissektion bei Patienten mit IPC und einem assoziierten duktalen Carcinoma in situ bzw. invasiven Karzinom ist. Auf Grund der Seltenheit von IPC und der verwirrenden histopathologischen Klassifikation und Stadieneinteilung gibt es bisher keine klaren Richtlinien für die IPC-Therapie.

aforementioned, Zumoff [6] argues that prolactin might protect against breast cancer when levels are low, rather than a prolactin excess increasing the risk of breast cancer. There have been many studies concerning the role of prolactin in male breast cancer, which have produced conflicting results $[5,7]$.

Papilloma appears to be encapsulated within the duct from which it arises. Apparently, a cyst containing a blood clot and an intracystic neoplasm (benign or carcinoma) should be included in the differential diagnosis [8]. IPCs are a small subgroup of breast carcinoma. In the case of local appearance

\section{KARGER \\ Fax +497614520714 \\ Information@Karger.de}

www.karger.com
(C) 2011 S. Karger GmbH, Freiburg

1661-3791/11/0065-0399\$38.00/0

Accessible online at:

www.karger.com/brc
Stamatakos Michael, MD, PhD

4th Department of Surgery

Medical School, University of Athens

Attikon Hospital, Athens, 12462, Greece

Tel. +306944133068

mixalislak@gmail.com 
Table 1. Classification of intracystic papillary carcinoma (IPC)

\begin{tabular}{ll}
\hline Papillary carcinoma & $\begin{array}{l}\text { diffuse type } \\
\text { localized type (IPC; solitary grossly evident } \\
\text { tumor in a cystic and dilated duct) }\end{array}$ \\
& pure IPC (IPC alone) \\
IPC & IPC with ductal carcinoma in situ \\
& IPC with invasive carcinoma \\
\hline
\end{tabular}

and lack of invasiveness, breast cancers with papillary proliferation arising within or on the wall of a large cyst $[9,10]$ are generally characterized by a favorable prognosis $[11,12]$. As mentioned previously, breast IPCs in males are rare and carry a good prognosis. In women, IPCs account for $0.5-2 \%$ of all breast cancers [11]. A higher risk ratio in men (5-7.5\%) has been suggested by some authors $[13,14]$. Moreover, IPCs seem to present more often in men with gynecomastia [15]. 'Confusion' is a common term associated with papillary breast lesions in the literature. The use of the traditional term 'intracystic papillary carcinoma' generally refers to a localized lesion in situ within a dilated duct, due to a cyst. Unfortunately, since the presence of a marked stromal response surrounding these lesions is quite common, the distinction between in situ and invasive papillary carcinoma is very difficult. Therefore, 3 IPC subgroups have been introduced which seem to be correlated with prognosis: IPC pure, IPC plus ductal carcinoma in situ (DCIS), and IPC with invasion (table 1). According to the aforementioned, the term 'papillary DCIS' suggests a more diffuse process involving multiple ducts compared to a localized lesion [16]. Hill et al. [17], using myoepithelial cell (MEC) staining, suggested a spectrum of progression types from in situ disease to invasive disease, showing that although a lesion might appear as a DCIS on histology, it has the potential to cause distant metastases. Distinguishing a papilloma from a papillary carcinoma through the existence or non-existence of the MEC layer is of utmost importance. Calponin, smooth-muscle myosin heavy chain (SMM-HC) cytoplasmic stains, and p63 nuclear stains can identify the lack of an intact basal MEC layer. This fundamental method has a relatively high sensitivity and denotes the invasiveness of the tumor cells in malignant papillary breast lesions [18]. Furthermore, recent studies have shown that in contrast to papillary DCIS, IPC does not appear to have a MEC layer surrounding the tumor nodules. This observation has led to the conclusion that in some cases, IPC may not actually be an in situ carcinoma but an encapsulated nodule of low-grade invasiveness or part of the spectrum of intermediate progression, between DCIS and invasive disease. Some pathologists now prefer the term 'encapsulated papillary carcinoma' to the more traditional 'intracystic papillary carcinoma' [19]. Data also suggests that loss of heterozygosity ( $\mathrm{LOH}$ ) on chromosome $16 \mathrm{q}$ is a useful marker for IPC, unlike intraductal papilloma which does not exhibit such characteristics. The use of polymerase chain reaction indicates in a more definite way the potential of malignancy in intracystic papillary lesions, as 16q LOH depicts malignancy [20].
The cornerstone of the treatment of pure IPC is local wide excision preferably without axillary dissection, given the absence of axillary involvement and the low recurrence rate after local excision [21, 22].

\section{IPCs and Hormone Receptors}

Male breast cancers have a high rate of hormone receptor expression. Approximately $90 \%$ of male breast cancers express the estrogen receptor, and $81 \%$ express the progesterone receptor [23]. Cancers of the male breast are significantly more likely than cancers of the female breast to express hormone receptors, even after adjustment for tumor stage, grade, and patient age [24]. The Her2/neu protooncogene is less likely to be overexpressed in cancers of the male breast. One series of 75 patients found that only $5 \%$ of male breast cancers overexpressed Her2/neu [25]. The role of the androgen receptor in male breast cancer is unclear. The reported rates of androgen receptor expression range from 34 to $95 \%$, but this receptor has not been associated with breast cancer prognosis [26, 27].

\section{Clinical Presentation}

Most patients present with a palpable breast lump. In addition to the clinical abnormalities felt on palpation, mild pain, bloody nipple discharge, and pruritus may also be present. The typical clinical presentation is an apparently benign and due to its underlying cystic nature well-localized lump. The literature suggests that the mean age of occurrence of IPC in males is 68.2 years [28].

\section{Diagnosis}

\section{Ultrasound}

Triple assessment is vital, and the goal is to achieve a preoperative diagnosis. Even if the radiological diagnosis of IPC is relatively difficult, radiology has been helpful in collecting data on imaging characteristics of these lesions. A hypoechoic area (representing the cyst) with soft tissue echoes projecting from the wall of the cyst (intracystic tumor) is the typical presentation of these lesions in the ultrasound examination [28]. It is of note that IPCs are highly vascularized tumors, demonstrating a characteristic blood flow pattern on color-flow studies, such as distinct vascular pedicles within the central core of the mass, enabling the identification of even very small IPCs.

\section{Mammography}

It is characterized by low specificity. Small IPCs, often mammographically absent, may escape the diagnosis. On the other hand, larger lesions may appear similar to any other focal, well-circumscribed, dense mass on mammography [29]. 
A minimal to moderate duct dilatation in a tapering band-like density pattern from the nipple towards the parenchyma can occur in either case. An irregular margin on mammography is highly suggestive of the presence of invasion, since IPC usually appears well-defined on mammography [30].

\section{Magnetic Resonance Imaging}

Magnetic resonance imaging (MRI) is increasingly used nowadays. MRI is more sensitive than computed tomography in detecting DCIS [31]. In younger patients, however, high background signals sometimes make it difficult to demonstrate attenuation related to DCIS because of the higher contrast of MRI [32, 33]. MRI usually reveals 3 variable patterns of intraductal papilloma: i) Papillomas may be small, smooth, enhancing masses at the posterior end of an enlarged duct, corresponding to the 'small lumenal mass' appearance of papilloma known from galactography. These 'small lumenal masses' are usually present in patients with abnormal nipple discharge. ii) Irregular enhancing masses are detected in patients without nipple discharge. Rapid enhancement and spiculation are usually demonstrated. These 'tumor-like' papillomas may mimic invasive breast cancer on MRI. iii) Papillomas might also appear occult on MRI, or be absent in either contrast-enhanced MRI or fat-suppressed T2-weighted MRI [34]. Contrast-enhanced MRI may show marked enhancement of cyst walls, septations, and mural nodules [35].

\section{Fine Needle Aspiration}

Fine needle aspiration (FNA) is an indispensable technique with high sensitivity and specificity and good cytohistological accordance in lesions of the male mammary gland [36, 37]. When ultrasound reveals cystic masses with mural nodules, and aspiration fluid is bloody, biopsy should be performed. It seems that there is no significant difference between the cytologic features of papillary lesions of the male breast and those of the female breast. However, when no cytologic feature can be used to distinguish benign from malignant papillary lesions, a constellation of features is proposed as highly indicative of malignancy. Hypercellularity, a unique population of neoplastic cells with moderate nuclear atypia, $3 \mathrm{D}$ papillae with and without fibrovascular cores, single intact columnar cells, and dissociated atypical single cells are the most important. In routine practice, however, FNA being often inaccurate is rarely diagnostic and an excisional biopsy is usually required to establish the diagnosis [38]. Some studies [1] demonstrated core biopsy to be effective in distinguishing papillary neoplasms from other diseases and in differentiating benign papillomas from papillary carcinoma.

\section{Differential Diagnosis}

Differentiation from gynecomastia and fibroadenoma is mandatory in the differential diagnosis of IPC. Smears of gynecomastia may be hypercellular, with crowded but flattened epithelium and stromal fragments. With regards to gynecomastia, although moderate to severe nuclear atypia may be present, atypical single epithelial cells and 3D groups are scarce, making the distinction from a papillary lesion possible. Fibroadenomas are uncommon in males, and typical FNA findings include hypercellularity and flat branching sheets of benign ductal cells, stromal fragments and bare nuclei. Single columnar cells and true fibrovascular cores are not detected [39].

\section{Therapy}

No definite guidelines have evolved regarding the management of IPC, due to various factors. The scarcity of IPC and the incomplete histological classification and detection of invasiveness in IPC are 2 of the main reasons of the lack of direction in how to treat this unusual disease. Grabowski et al. [40] have confirmed that surgery is the cornerstone of treatment, which can be either conservative or a mastectomy. Since the prognosis of IPC is excellent with low locoregional and distant recurrence rates, mastectomy is usually not necessary unless technically unavoidable. As far as axillary node metastasis is concerned, it is present in up to $14 \%$ of the cases [40], and therefore most authors recommend an axillary staging procedure. However, some authors propose that IPC should be generally treated as an in situ disease and consequently axillary surgery is not recommendable [41]. Given the overall good prognosis and the fact that no adjuvant treatment has been shown to increase cancer-free survival, there is concern regarding potential overtreatment. However, it should be mentioned that approximately half of all IPC cases are associated with DCIS or invasive carcinoma (multiform or not) which are undetectable with modern radiologic tests. The role of sentinel node biopsy has not yet been assessed in this disease, but data suggests that sentinel node biopsy may be an excellent alternative to radical axillary dissection in patients with IPC and associated invasive carcinoma. Lumpectomy is an option for pure IPC. However, the role of radiotherapy in these patients remains undefined. As far as the use of adjuvant endocrine therapy is concerned, no clear indication exists, even among patients with estrogen receptor-positive tumors. In studies concerning female patients, it has been difficult to identify a group that did not benefit from some form of adjuvant therapy. However, the current evidence on treatment of male breast cancer shows that the addition of hormonal treatment does not appear to have an impact on treatment outcome [19]. Alternatively, Fayanju et al. [42] recently reviewed the adjuvant treatment usually applied in IPC and found that patients with DCIS or microinvasive disease in association with IPC were more likely to receive radiotherapy and tamoxifen. A new proposed algorithm for the treatment of papillomas is shown in table 2 [43]. 
Table 2. Algorithm for the treatment of papillomas

Discharge: physical examination, mammography, and/or ultrasound

No significant abnormality, benign: $M D+$ ductal lavage +/- biopsy

Evidence of malignancy

MD-guided BCS, mastectomy

No evidence of malignancy

Symptomatic: MD-guided microdochectomy

Not symptomatic: reassure, conservative treatment

Significant abnormality ${ }^{a}$ : imaging-guided core biopsy/mammotome-

MRI-MD and ductal lavage biopsy

Evidence of malignancy

MD-guided BCS, mastectomy

No evidence of malignancy

Symptomatic: MD-guided microdochectomy

Not symptomatic: reassure, conservative treatment

${ }^{a}$ Microcalcifications/indeterminate mass/malignant cytology.

$\mathrm{MD}=$ Mammary ductoscopy; BCS = breast-conserving surgery;

$\mathrm{MRI}=$ magnetic resonance imaging.

\section{Prognosis}

IPC typically occurs in older men and has an excellent prognosis. The reported 10 -year survival rate for IPC is $100 \%$, the recurrence-free survival rate is 96 and $77 \%$ at 2 and 10 years, respectively [44]. Overall survival rates for men with breast carcinoma, stratified by stage of disease, are lower than those of women with breast carcinoma. However, assumptions should not be made based on these results, since the differences are most likely to be due to the higher age distribution in male patients and the lower life expectancy in men. Because of the favorable prognosis of this tumor, histological findings are definitive for the decision making regarding the surgical procedure [19].

\section{Conclusion}

IPC in the male mammary gland is a very uncommon disease with only a few case presentations having been published in the world literature. In the case of high clinical suspicion, triple assessment (i.e. clinical examination, radiological and histological assessment) is invaluable for establishing the diagnosis, given that IPCs are extremely rare. To date, no clear and definitive guidelines regarding optimal IPC treatment exist. The achievement of adequate surgical margins in conservative surgical treatment is paramount. It is well documented that the low frequency of axillary node metastases in cases of pure IPC does not justify axillary lymph node dissection. Although the role of sentinel node biopsy has not been evaluated in this disease, it appears that sentinel node biopsy may be an excellent alternative to radical axillary dissection in patients with IPC and associated DCIS or invasive carcinoma. In cases of nipple discharge as an early sign or a strong family history of male breast cancer, genetic testing and risk-reducing mastectomy should also be considered.

\section{Disclosure Statement}

No competing financial interests exist.

\section{References}

1 Kinoshita T, Fukutomi T, Iwamoto E, et al.: Intracystic papillary carcinoma of the breast in a male patient diagnoses by core needle biopsy: a case report. Breast 2005;14:322-4.

2 Haagensen CD: Disease of the Breast. Philadelphia, PA, WB Saunders, 1986.

$\checkmark 3$ Rose DP, Pruitt B: Plasma prolactin levels in patients with breast cancer. Cancer 1981;48:2687-91.

4 Ingram DM, Nottage EM, Roberts AN: Prolactin and breast cancer risk. Med J Aust 1990;153:469_ 73.

5 Okada K, Kajiwara S, Tanaka H, et al.: Synchronous bilateral noninvasive ductal carcinoma of the male breast: a case report. Breast Cancer 2003;10:163-5.

$\checkmark 6$ Zumoff B: Hormonal profiles in women with breast cancer. Obstet Gynecol Clin North Am 1994:21:751-72.

7 Haga S, Watanabe O, Shimizu T, et al.: Breast cancer in a male patient with prolactinoma. Surg Today 1993;23:251-5.

8 Yamamoto H, Okada Y, Taniguchi H, et al.: Intracystic papilloma in the breast of a male given longterm phenothiazine therapy: a case report. Breast Cancer 2006;13:84-8.

$\checkmark 9$ Sinha S, Hughes RG, Ryley NG: Papillary carcinoma in a male breast cyst: a diagnostic challenge. Ann R Coll Surg Engl 2006;88:w3-5.
Andres B, Aguilar J, Torroba A, et al.: Intracystic papillary carcinoma in the male breast. Breast $\mathrm{J}$ 2003;9:249-50.

11 Czernobilsky B: Intracystic carcinoma of female breast. Surg Gynecol Obstet 1967;124:93-8.

12 Carter D, Orr SL, Merino M: Intracystic papillary carcinoma of the breast after mastectomy, radiotherapy or excision biopsy alone. Cancer 1983;52:14-9.

13 Heller KS, Rosen PP, Schottenfeld D, et al.: Male breast cancer: clinicopathologic of 97 cases. Ann Surg 1978;188:60-5.

14 Wolff M, Renis MS: Breast Cancer in Males: Clinicopathologic Study of 40 Patients. New York, NY, Masson Publishing, 1981

15 Liechty RD, Davis J, Gleysteen J: Cancer of the male breast: forty cases. Cancer 1967;20:1617-24.

16 Collins LC, Carlo VP, Hwang H, et al.: Intracystic papillary carcinomas of the breast: a reevaluation using a panel of myoepithelial cell markers. Am J Surg Pathol 2006;30:1002-7.

17 Hill CB, Yeh IT: Myoepithelial cell staining patterns of papillary breast lesions: from intraductal papillomas to invasive papillary carcinomas. Am J Clin Pathol 2005;123:36-44.

18 Romics L, O'Brien ME, Relihan N, et al.: Intracystic papillary carcinoma in a male as a rare presentation of breast cancer: a case report and literature review. J Med Case Reports 2009;3:13.
9 Anderson WF, Devesa SS: In situ male breast carcinoma in the Surveillance, Epidemiology, and End Results database of the National Cancer Institute. Cancer 2005;104:1733-41.

20 Tsuda H, Uei Y, Fukutomi T, et al.: Different incidence of loss of heterozygosity on chromosome 16q between intraductal papilloma and intracystic papillary carcinoma of the breast. Jpn J Cancer Res 1994;85:992-6.

21 Tochika N, Takano A, Yoshimoto T, et al.: Intracystic carcinoma of the male breast: report of a case. Surg Today 2001;31:806-9.

22 Harris KP, Faliakou EC, Exon DJ, et al.: Treatment and outcome of intracystic papillary carcinoma of the breast. Br J Surg 1999;86:1274.

23 Giordano SH, Cohen DS, Buzdar AU, et al.: Breast carcinoma in men: a population-based study. Cancer 2004;101:51-7.

24 Wick MR, Sayadi H, Ritter JH, et al.: Low-stage carcinoma of the male breast. A histologic, immunohistochemical, and flow cytometric comparison with localized female breast carcinoma. Am J Clin Pathol 1999;111:59-69.

25 Muir D, Kanthan R, Kanthan SC: Male versus female breast cancers. A population-based comparative immunohistochemical analysis. Arch Pathol Lab Med 2003;127:36-41. 
26 Kidwai N, Gong Y, Sun X, et al.: Expression of androgen receptor and prostatespecific antigen in male breast carcinoma. Breast Cancer Res 2004;6:R18-R23.

27 Pich A, Margaria E, Chiusa L, et al.: Androgen receptor expression in male breast carcinoma: lack of clinicopathological association. Br J Cancer 1999;79:959-64.

28 Jones BM, Bradbeer JW: The presentation and progress of macroscopic breast cyst. Br J Surg 1980;67:669-71.

29 Ganesan S, Karthik G, Joshi M, et al.: Ultrasound spectrum in intraductal papillary neoplasms of breast. Br J Radiol 2006;79:843-9.

30 Estrabrook A, Asch T, Gump F, et al.: Mammographic features of intracystic papillary lesion. Surg Gynecol Obstet 1990;170:113-6.

31 Blaumeiser B , Tjalma WA, Verslegers I, et al.: Invasive papillary carcinoma of the male breast. Eur Radiol 2002;12:2207-10.

32 Shimauchi A, Yamada T, Sato A, et al.: Comparison of MDCT and MRI for evaluating the intraductal component of breast cancer. Am J Roentgenol 2006;187:322-9.

33 Amemiya T, Oda K, Satake H, et al.: A case of intracystic papillary carcinoma accompanying widespread ductal carcinoma in situ. Breast Cancer 2007;14 312-6.

34 Daniel BL, Gardner RW, Birdwell RL, et al.: Magnetic resonance imaging of intraductal papilloma of the breast. Magn Reson Imaging 2003;21:887-92.

35 Wagner AE, Middleton LP, Whitman GJ: Intracystic papillary carcinoma of the breast with invasion. AJR Am J Roentgenol 2004;183:1516.

36 Joshi A, Kapila K, Verma K: Fine-needle aspiration cytology in the management of male breast masses. Nineteen years experience. Acta Cytol 1999;43:334-8.

37 Dei Tos AP, Della Giustina D, et al.: Aspiration biopsy cytology of malignant papillary breast neoplasms. Diagn Cytopathol 1992;8:580-4.

-38 Reid-Nicholson M, Tong G, Cangiarella J, et al.: Cytomorphologic features of papillary lesions of the male breast. Cancer Cytopathol 2006;108:222-30.

39 Siddiqui MT, Zakowski MF, Ashfaq R, et al.: Breast masses in males: multiinstitutional experience on fine-needle aspiration. Diagn Cytopathol 2002;26: 87-91.

40 Grabowski J, Salzstein SL, Sadler GR, et al.: Intracystic papillary carcinoma: a review of 917 cases. Cancer 2008;113:916-20.

41 Dragoumis DM, Tsiftsoglou AP: Intracystic papillary carcinoma associated with ductal carcinoma in situ in a male breast. J Postgrad Med 2008;54:39-40.

42 Fayanju OM, Ritter J, Gillanders WE, et al.: Therapeutic management of intracystic papillary carcinoma of the breast: the roles of radiation and endocrine therapy. Am J Surg 2007;194:497-500.

43 Mugler KC, Marshall C, Hardesty L, et al.: Intracystic papillary carcinoma of the breast: differential diagnosis and management. Oncology (Williston Park) 2007;21:871-6.

44 Solorzano CC, Middleton LP, Hunt KK, et al.: Treatment and outcome of patients with intracystic papillary carcinoma of the breast. Am J Surg 2002; 184:364-8. 